\title{
CORRECTION
}

View Article Online

View Journal I View Issue

Check for updates

Cite this: J. Mater. Chem. A, 2018, 6 , 23904

DOI: $10.1039 / c 8 t a 90255 k$

www.rsc.org/MaterialsA

\section{Correction: A high temperature stable piezoelectric strain of KNN-based ceramics}

Zhenyong Cen, (D) a Yu Huan, ${ }^{b}$ Wei Feng, ${ }^{a}$ Yan Yu, ${ }^{a}$ Peiyao Zhao, ${ }^{a}$ Lingling Chen, ${ }^{a}$ Chaoqiong Zhu, ${ }^{a}$ Longtu $\mathrm{Li}^{\mathrm{a}}$ and Xiaohui Wang ${ }^{\text {*a }}$

Correction for 'A high temperature stable piezoelectric strain of KNN-based ceramics' by Zhenyong Cen et al., J. Mater. Chem. A, 2018, 6, 19967-19973.

The authors regret an error in the labelling of Miller indices in Fig. 3(b). The corrected version of Fig. 3 is shown below.
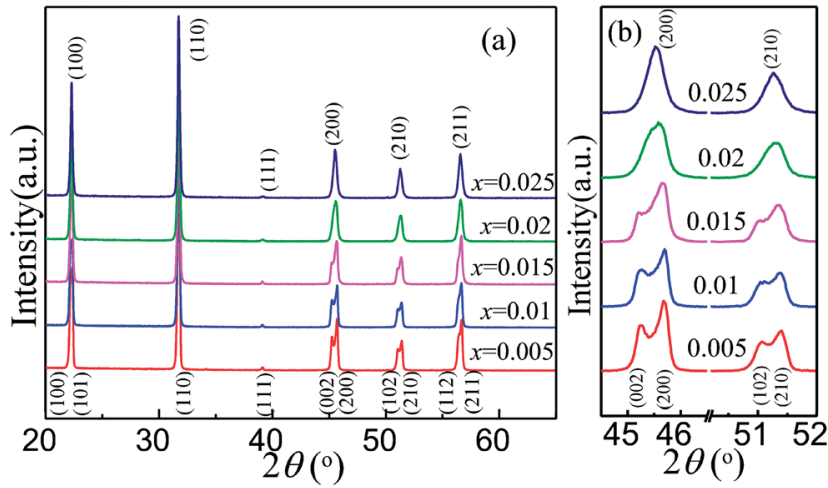

Fig. 3 Room-temperature XRD patterns of $(1-x)(0.96 K N N T-0.04 B N K Z)-x C Z$ ceramics (a) $2 \theta=20-65^{\circ}$. (b) $2 \theta=44-53^{\circ}$.

The Royal Society of Chemistry apologises for these errors and any consequent inconvenience to authors and readers. 